\title{
Detection of Mycoplasmas in Patients with Amyotrophic Lateral Sclerosis
}

\author{
Constantino Gil1*, Alma Aurora Sánchez González², Isidro Lecona León³, \\ Antonio Rivera1, Rayo Santellán Olea1, Lilia Cedillo ${ }^{1}$ \\ ${ }^{1}$ Centro de Investigaciones en Ciencias Microbiológicas, Instituto de Ciencias, Benemérita Universidad \\ Autónoma de Puebla, Edificio 103J, Ciudad Universitaria, Col. San Manuel, Puebla Pue, México \\ ${ }^{2}$ Escuela de Biología, Benemérita Universidad Autónoma de Puebla, Edificio 112A Ciudad Universitaria, Col. San \\ Manuel, Puebla Pue, México \\ ${ }^{3}$ Servicio de Neurología, Centro Médico Nacional Manuel Ávila Camacho, IMSS, Puebla, México \\ Email: ${ }^{*}$ constantino.gil@correo.buap.mx
}

Received 26 June 2014; revised 24 July 2014; accepted 25 August 2014

Copyright (C) 2014 by authors and Scientific Research Publishing Inc.

This work is licensed under the Creative Commons Attribution International License (CC BY).

http://creativecommons.org/licenses/by/4.0/

(c) (i) Open Access

\begin{abstract}
Amyotrophic Lateral Sclerosis (ALS) is a progressive degenerative disease of the motor neurons and the cause is unknown. Diverse factors such as genetic defects, nutritional deficiencies, head trauma, environmental toxin, autoimmune responses and viral and bacterial infections are involved. Mycoplasmas have been implicated as causal agents of different illnesses in human. The purpose of this study was to investigate the presence of mycoplasmas in the bloodstream of patients with ALS. Patients with ALS and healthy individuals were included in the study. A blood sample was taken in tubes with or without anticoagulant. Mycoplasmas were detected by culture or direct PCR, and the presence of antibodies IgM and IgG against LAMPs of these microorganisms by Western blot. Cultures for aerobic facultative bacteria were also done. Blood samples from 13 patients and 44 healthy individuals were screened. All blood cultures for non-fermentative mycoplasmas and aerobic facultative bacteria were negative. Cultures for fermentative mycoplasmas were considered positive after identification of mycoplasmal DNA by PCR. Mycoplasma sp. was detected by culture or direct PCR in $6 / 13(46 \%)$ patients and in $4 / 44(9 \%)$ of healthy individuals. $M$. fermentans was detected by PCR using specific primers in six patients and in two healthy individuals. IgM against LAMPs of $M$. fermentans were detected in 6/13 (46\%) blood samples from patients and in 13/44 (30\%) from healthy individuals, while. IgG was detected in 4/13 (31\%) patients and in $3 / 44(7 \%)$ healthy individuals. The results of this study show that mycoplasmas cause a systemic infection and could play a role in the origin or progression of the ALS.
\end{abstract}

\footnotetext{
*Corresponding author.
}

How to cite this paper: Gil, C., González, A.A.S., León, I.L., Rivera, A., Olea, R.S. and Cedillo, L. (2014) Detection of Mycoplasmas in Patients with Amyotrophic Lateral Sclerosis. Advances in Microbiology, 4, 712-719. 


\section{Keywords}

\section{Amyotrophic Lateral Sclerosis, Mycoplasmas, Immune Response}

\section{Introduction}

Amyotrophic lateral sclerosis (ALS) or Lou Gehrig's disease is a neurodegenerative disease affecting central and peripheral motor neurons. The main features of ALS are gradual progressive weakness and paralysis of muscles due to destruction of upper motor neurons in the motor cortex and lower motor neurons in brain stem and spinal cord, these affectations resulting in death. Clinical, pathological and genetic studies indicate that ALS should be considered a syndrome rather than a single disease entity. Clinical presentation and progression of ALS varies considerably, the course is progressive, and over $60 \%$ of patients die within 3 years of presentation and up to $10 \%$ survive for more than 8 years. However, clinical picture of ALS can vary, depending on the location and progression of pathological changes found in nervous tissue [1] [2]. ALS diagnosis is complicated due to variability of the signs and symptoms of the disease. The first guidelines were established in the "El Escorial", but only with research and clinical purposes, the importance of the laboratory was included in the Airlie House criteria and the role of neurophysiology diagnostic was included in the Awaji-Shima criteria, so the diagnosis of ALS involve clinical and electrophysiological tests [3]. Epidemiological studies in ALS have been complicated, because several factors are unknown, for example: date of disease onset, duration between onset of pathological changes and manifestation of clinical disease, however, rigorous designs of epidemiological studies have provided evidences in support to understand causative mechanisms of ALS. The risk of developing ALS peaks between the ages of 50 years and 75 years [1]. Incidence of ALS in people worldwide is not known, but men had higher incidence than women ( 3 to 2.4 per 100,000), before the age of 65 , slightly more men than women develop ALS. This sex difference disappears after age 70 [4] [5]. In 90 to 95 percent of all ALS cases, the disease apparently occurs at random with no clear risk factors. Individuals with this sporadic form of the disease do not have a family history of ALS, and their family members are not considered to be at increased risk for developing it. On the other hand, 5 to 10 percent of all ALS cases are inherited. The familial form of ALS usually results from a pattern of inheritance that requires only one parent to carry the gene responsible for the disease. Mutations in more than a dozen genes have been found to cause familial ALS [5]. Diverse factors such as genetic mutations such as gene mutations implicated in defects in protein recycling, nutritional deficiencies, head trauma, environmental toxin, autoimmune responses and viral and bacterial infections may be involved. Enterovirus, Chlamydia pneumoniae, Borrelia burgdorferi, HIV, HTLV-1 and mycoplasmas have been implicated. Mycoplasmas are considered causal agents of respiratory, genitourinary, neurodegenerative diseases, they also have been associated with Gulf War syndrome and rheumatoid arthritis and in acquired immunodeficiency syndrome. Systemic mycoplasmal infections in ALS patients have been documented [6]-[9].

\section{Objective}

The purpose of this study was to detect a systemic infection due to mycoplasmas in patients with ALS.

\section{Materials and Methods}

\subsection{Patients}

Thirteen patients (4 female and 9 males) with diagnostic of ALS who attended the Neurology Service of the Hospital Manuel Avila Camacho del Instituto Mexicano del Seguro Social in Puebla, México were included in the study. A Neurologist examined the patients and all of them fulfilled "El Escorial" criteria modified by the World Federation of Neurology [3]. The patients' ages ranged between 52 - 74 years old.

\subsection{Healthy Individuals}

Forty-four healthy individuals (19 females and 25 males) without ALS, Parkinson disease, AIDS or other neurodegenerative disease were included in the study. Ages in the healthy individuals ranged between 22 and 60 years old. No healthy individuals were under antibiotic or other drug treatment. 


\subsection{Ethics}

The Ethical Committee on Health of the Centro Médico Nacional Manuel Avila Camacho, Puebla, approved this study (reg. 2101) and a consent letter was signed from all individuals.

\subsection{Specimens}

Peripheral whole blood samples from patients and healthy individuals were collected in order to detect mycoplasmas by culture and direct PCR. Antibodies specific to $M$. fermentans were also investigated by Western blot assay. Blood samples were collected in citrate-containing or non-anticoagulant tubes. Sera were stored at $-20^{\circ} \mathrm{C}$ until use.

\subsection{Mycoplasmal Culture}

One hundred microliters of plasma of patients and healthy individuals were dip-inoculated in $900 \mu \mathrm{L}$ of two different media: SP4 medium with glucose and SP4 medium with arginine, in order to isolate fermentative and non-fermentative mycoplasmas respectively. An SP4 tube with each medium was incubated as control. Three serial ten-fold dilutions were incubated at $37^{\circ} \mathrm{C}$ until the indicator phenol red changed to yellow for fermentative mycoplasmas or red for non-fermentative, which indicate mycoplasma growth, on the other hand, cultures were considered negative when the indicator did not change after 30 days for M. pneumoniae and M. fermentans and 4 days for $M$. hominis. Control cultures were prepared as follows: one hundred microliters of M. fermentans PG18, M. pneumoniae Eaton strain and M. hominis were dip-inoculated into $900 \mu \mathrm{L}$ of plasma, and three serial ten-fold dilutions were done into SP4 media with glucose or arginine and incubated at $37^{\circ} \mathrm{C}$ for 48 hours or until the indicator changed showing mycoplasma growth. Likewise, one hundred microliters of each reference strains were dip-inoculated into $900 \mu \mathrm{L}$ of the SP4 media with the respective substrate. Dilutions are done when tissues or corporal fluids are cultivated, because some inhibitory substances for mycoplasmas may be present. Positive mycoplasma cultures were confirmed using the PCR technique. All the blood samples were cultured on blood agar plates to detect aerobic facultative bacteria.

\subsection{DNA Extraction from Blood Samples}

Red blood cells $(2.5 \mathrm{~mL})$ were lysed with nanopure water $(10 \mathrm{~mL})$ at room temperature and centrifuged $(3000 \mathrm{~g}$, $\left.10 \mathrm{~min}, 4^{\circ} \mathrm{C}\right)$. The pellet containing white cells was treated as follow: Triton X-100 $(1 \%, 10 \mathrm{~mL})$ was added and mixed gently for $5 \mathrm{~min}$. After centrifugation $\left(3000 \mathrm{~g}, 10 \mathrm{~min}, 4^{\circ} \mathrm{C}\right)$, SDS $(1 \%, 10 \mathrm{~mL})$ was added and mixed gently for $10 \mathrm{~min}, \mathrm{NaCl}(0.1 \mathrm{M}, 10 \mathrm{~mL})$ was added for $10 \mathrm{~min}$ followed by $10 \mathrm{~mL}$ of cold ethanol. After centrifugation $\left(10,000 \mathrm{~g}, 10 \mathrm{~min}, 4^{\circ} \mathrm{C}\right)$, the supernatant was discarded and the DNA was recovered in $500 \mu \mathrm{L}$ of nanopure water and stored at $-20^{\circ} \mathrm{C}$. DNA was also extracted from a $1.4 \mathrm{~mL}$ whole blood sample seeded with 100 $\mu \mathrm{L}$ of $M$. fermentans PG18 for use as a positive control sample.

\subsection{DNA Extraction from Mycoplasmal Cultures}

DNA was extracted from presumptive Mycoplasma-positive cultures as follow: $2 \mathrm{ml}$ of culture were centrifuged (12,000 g, 20 min., $4^{\circ} \mathrm{C}$ ), the supernatant was discarded and the pellet was suspended in $100 \mu \mathrm{L}$ of a solution containing: $10 \mathrm{mM}$ Tris-HCl pH 8.3, $100 \mathrm{mM} \mathrm{KCl}, 2.5 \mathrm{mM} \mathrm{MgCl}_{2}, 1 \%$ Tween-20, 1\% Triton X-100 and 0.5 $\mathrm{mg} / \mathrm{mL}$ of proteinase $\mathrm{K}$. Samples were heated at $60^{\circ} \mathrm{C}$ for $60 \mathrm{~min}$ and immediately brought to $90^{\circ} \mathrm{C}$ for $10 \mathrm{~min}$. and then placed in ice bath for $20 \mathrm{~min}$ and stored at $-20^{\circ} \mathrm{C}$ until use.

\subsection{PCR Assays}

Mycoplasma sp. DNA was detected using 16s RNA gene primers AR1 (sense)5'ATGRGGRTGCGGCGTATTA G3' and AR2 (antisense)5'CKGCTGGCACATAGTTAGCCRT-3' according to Shidu et al. [10]. Primers used to identify M. fermentans were RW004 (sense)5'-GGACTATTGTCTAAACAATTTCCC-3', RW005(antisense)5'GGTTATTCGATTTCTAAATCGCCT-3' [11] and for M. pneumoniae were MP5-1 (sense)5'-GAAGCTTATGG TACAGGTTGG-3' and MP5-2 (antisense)5'-ATTACCATCCTTGTTGTAAGG-3' [12] [13]. Amplification was performed in a total volume of $20 \mu \mathrm{L}$ containing $10 \mu \mathrm{L}$ of Pyro Start, $1.3 \mu \mathrm{L}$ of each primer, $2.4 \mu \mathrm{L}$ of sterile water and $5 \mu \mathrm{L}$ of the sample problem. The sample to be analysed was always added last. A diluted lysate of $M$. 
fermentans PG18 corresponding to 100 colour-changing units and sterile water were used as positive and negative controls, respectively. Amplification consisted of a 10-min thermal delay step at $95^{\circ} \mathrm{C}$, followed by 40 cycles comprising a $20 \mathrm{~s}$ denaturation step at $95^{\circ} \mathrm{C}$, a 1 -min annealing step at $62^{\circ} \mathrm{C}$, a 1 -min elongation step at $72^{\circ} \mathrm{C}$, and a final 4-min elongation step at $72^{\circ} \mathrm{C}$ PCRs. DNA amplification was performed with an automated thermocycler (Techne PC-412). PCR products were anlysed by $2 \%$ agarose gels electrophoresis and ethidium bromide staining [10].

\subsection{Lipid-Associated Membrane Proteins (LAMPs) Preparation}

M. fermentans PG18 pellet from $500 \mathrm{~mL}$ of culture broth was suspended in $5 \mathrm{~mL}$ of phosphate-buffered saline $\mathrm{pH} 7.2,0.015 \mathrm{M}$ (PBS) solubilized by adding TX-114 (Sigma Co.) to a final concentration of $2 \%$ and incubated at $4^{\circ} \mathrm{C}$ for $2 \mathrm{~h}$. To prepare total protein, 2.5 volumes of ethanol were added and the mixture was incubated at $4^{\circ} \mathrm{C}$ overnight. Precipitated proteins were pelleted by centrifugation $\left(10,000 \mathrm{~g}, 20 \mathrm{~min}, 4^{\circ} \mathrm{C}\right)$ and suspended in $2 \mathrm{~mL}$ of PBS. To prepare LAMPs, the TX-114 lysate was incubated at $37^{\circ} \mathrm{C}$ for $20 \mathrm{~min}$ for phase separation. After centrifugation $\left(10,000 \mathrm{~g}, 20 \mathrm{~min}, 4^{\circ} \mathrm{C}\right)$ the upper aqueous phase was removed and replaced with $2 \mathrm{~mL}$ of PBS. The solution was stored at $-20^{\circ} \mathrm{C}$ until use.

\subsection{Antibody-Specific Immunoblotting Assay}

LAMPSs were separated by SDS-polyacrylamide gel electrophoresis (12\%) under reductions conditions, transferred onto $0.45-\mu \mathrm{m}$ nitrocellulose membranes (NC) using a Cleaver Scientific Ltd system. The antibodies were detected by incubating 2 NC strips in each patient's serum diluted 1:100 in PBS at $37^{\circ} \mathrm{C}$ for $2 \mathrm{~h}$. Peroxidaseconjugates anti-human IgM or IgG were diluted 1:5000 in PBS and one strip was used in order to detect every one of the antibody class. Peroxidase substrate was prepared according to manufacturer (Sigma Co.) and the bound peroxidase activity was visualized using the incubation of the NC strips for 5 to 20 min. at room temperature.

\subsection{Statistical analysis}

Chi squared test was done in order to compare the presence of mycoplasmas in patients and healthy individuals. Chi squared test was also calculated in order to associate the presence of antibodies in patients and healthy individuals.

\section{Results}

\subsection{Patients}

Thirteen patients with ALS were included in the study; all of them had varying duration of the disease and illness severity, duration ranged from one month to 8 years (Table 1).

\subsection{Mycoplasmal Culture}

All of the blood samples from patients and healthy individuals were negative for mycoplasma culture in SP4 media with arginine and for aerobic facultative bacteria. Eight blood samples from patients and nine from healthy individuals were considered presumptive positive cultures for Mycoplasma genus in SP4 media with glucose because they changed the colour indicator of the media. Mycoplasmal DNA was identified using AR1 and AR2 genus specific primers in six blood samples from patients and four blood samples from healthy individuals. M. fermentans was identified in all blood samples from patients and in two from healthy individual and Mycoplasma spp. in the other two (Table 2 and Figure 1).

\subsection{Detection of Mycoplasmal DNA by Direct PCR}

AR1 and AR2 genus-specific primers, which amplify a 16s RNA gene fragment, were used to detect mycoplasmas in peripheral blood samples. Mycoplasma genus sequence was amplified in 6/13 (46\%) blood samples from patients and 4/44 (9\%) blood samples from healthy individuals. All blood samples from patients and two from healthy individuals were positive for $M$. fermentans; the other two from healthy individuals were not identified 
Table 1. Features of patients with ALS included in the study.

\begin{tabular}{ccccc}
\hline Patient number & Age/years & Sex & Years of disease & Illness severity \\
\hline E-M-73 & 73 & Male & 2 & S \\
A-M-54 & 54 & Male & 7 & M \\
MG-F-65 & 65 & Female & 5 & S \\
S-M-74 & 74 & Male & 3 & M \\
JC-M-58 & 58 & Male & 8 & M \\
E-M-63 & 63 & Male & 5 \\
R-M-56 & 56 & Male & 3 & L \\
EN-M-56 & 56 & Male & 0.5 & L \\
G-F-55 & 55 & Female & 3 & S \\
L-F-64 & 64 & Female & 0.1 & S \\
J-M-68 & 68 & Male & 3 & S \\
P-F-53 & 53 & Female & 3 & L \\
V-M-52 & 52 & Male & 3 & L \\
\hline
\end{tabular}

$\mathrm{S}=$ severe disability; $\mathrm{M}$ = medium disability; $\mathrm{L}$ = light disability.

Table 2. Identification of mycoplasmas in blood samples from patients and healthy individuals by culture or direct PCR.

\begin{tabular}{ccccc}
\hline & \multicolumn{2}{c}{ Mycoplasmas culture } & \multicolumn{2}{c}{ Direct PCR } \\
\cline { 2 - 4 } & Mycoplasma sp. & M. fermentans & Mycoplasma sp. & M. fermentans \\
\hline Patients & $6 / 13(46 \%)$ & $6 / 13(46 \%)$ & $6 / 13(46 \%)$ & $6 / 13(46 \%)$ \\
Healthy individuals & $4 / 44(9 \%)$ & $2 / 44(4.5 \%)$ & $4 / 44(9 \%)$ & $2 / 44(4.5 \%)$ \\
\hline
\end{tabular}

${ }^{*}$ Cultures were considered positives after identification of mycoplasmal DNA by PCR.

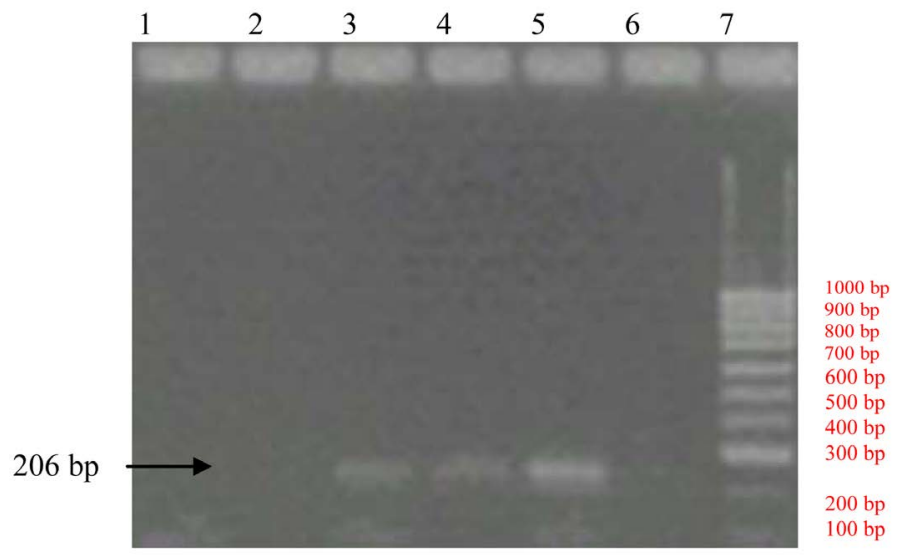

Figure 1. Detection of mycoplasmas in patients by PCR, only M. fermentans was identified using primers RW004 and RW005. Line 1-2 negative samples, line 3-4 positive samples, line 5 positive control, line 6 negative control and line 7 molecular weight markers.

(Table 2 and Figure 1). In order to associate the presence of mycoplasmas or $M$. fermentans to patients, Chi square was calculated, $P<0.0001$ was obtained, suggesting that there is an association between the presence of mycoplasmas to patients with ALS. 


\subsection{Antibody-Specific Immunoblotting Assay}

IgM-specific to LAMPs of M. fermentans PG18 was detected in sera from 6/13 (46\%) patients with ALS and $3 / 44$ (7\%) healthy individuals, while IgG was detected in sera from 4/13 (31\%) patients and in sera from 3/44 (7\%) healthy individuals (Table 3). Figure 2 shows representative results of immunobloting assay. Chi square was calculated and there was significant difference $(P<0.05)$ suggesting that there was an association between the presences of antibodies against mycoplasma in patients.

\section{Discussion}

Although in the last years, there was progress about understanding the pathophysiology of ALS, diverse factors like genetic mutations, gene mutations implicate defects in protein recycling, nutritional deficiencies, head trauma, environmental toxin, viral and bacterial infections, autoimmune responses, autotoxicity and inflammatory response are involved [5]. Respect to infectious agents, at the present there are not any irrefutable data concerning the involvement of infectious agents in the pathogenesis of ALS, however, mycoplasmas have been involved as possible agents since several studies show their presence in patients with central nervous system diseases [7]-[9]. In this study, we included 13 patients with ALS, 9 male and 4 female, the age ranged between 52 74 years old with different severity of the disease. There was no association between time of the onset and severity of the disease. Some patients had 3 years since ALS was diagnosed and they show severe incapacity, while others had seven or more years and they do not show severe incapacity. Miller et al. 2004 and Flores et al. 2005 reported similar results, they showed that sporadic ALS is present in people older than 40 years old and there are not relationship between time of onset and severity of the disease [2] [14].

We screened blood samples from patients with ALS and healthy people for aerobic facultative bacteria by culture and for mycoplasmas by culture, direct PCR and immunological assays. All cultures for aerobic facultative bacteria were negative. Mycoplasmas are fastidious bacteria difficult to culture, and identify, so we used

Table 3. Antibodies-specific to LAMPs of $M$. fermentans by immunobloting assay.

\begin{tabular}{ccc}
\hline & & SERA \\
\cline { 2 - 3 } & IgM & IgG \\
Patients & $6 / 13(46 \%)$ & $4 / 13(31 \%)$ \\
Healthy individuals & $3 / 44(7 \%)$ & $3 / 44(7 \%)$ \\
\hline
\end{tabular}



Figure 2. Detection of IgG-specific to LAMPS of M. fermentans PG18. Line 1 LAMPS, Line 2-6 positive sera from patients, line 7-9 negative sera from patients. 
culture and direct PCR in order to detect their presence. SP4 media with glucose or arginine were used in order to isolate mycoplasmas, however, only presumptive positive cultures were detected in SP4 medium with glucose, all SP4 medium with arginine were negative. AR1 and AR2 primers have been reported as specific to the Mycoplasma genus, they amplify 16s RNA gene nucleotide sequences of 30 different species [9]. Using these primers Mycoplasma spp. DNA was detected in $46 \%$ of patients and $9 \%$ of healthy individuals. The identification of species was done using species-specific primers for M. pneumoniae and M. fermentans, we detected M. fermentans in $46 \%$ of patients with ALS and in 4.5\% in healthy individuals and 4.5\% of Mycoplasma spp. Nicolson, et al. 2002, studied two populations of patients with ALS, Gulf War veterans and civilians. They showed the presence of mycoplasmas in $80 \%$ of Gulf War veterans and in $9 \%$ of the civilians, $M$. fermentans was the main mycoplasma isolated followed by M. pneumoniae and M. hominis [15]. Flores, et al. 2005, performed a casecontrol study in which they showed the presence of Mycoplasma spp. DNA in 50\% of the patients with ALS and in 10.9\% in controls. They did not find statistical difference between the presence of Mycoplasma spp. DNA and severity of the disease [14]. Although other pathogens like Enterovirus, Chlamydia pneumoniae, Borrelia burgdorferi, HIV-I, HTLV-1 have been implicated [7]-[9], in this study we only searched the presence of mycoplasmas and aerobic facultative bacteria.

Mycoplasmas have the ability to induce non-specific immune and inflammatory responses, because they are able to induce cytokine production, activate monocyte/macrophages, nonspecific polyclonal B and T lymphocytes and glial cells. On the other hand, mycoplasmas are able to avoid immune response by phase or antigenic variation. Lipid-associated membrane proteins (LAMPs) are the major antigens of mycoplasmas [16]. These mycoplasmal antigens have been implicated in some pathogenic effects and as targets of humoral immune response. Infections produced by mycoplasmas tended to chronicity, so the continuous production of nonspecific or specific antibodies can lead to hypersensitivity or autoimmune reaction, which may involve mycoplasmas as triggering or exacerbation agents of rheumatoid arthritis (RA) or systemic lupus erythematosus (SLE). Humoral immune response in patients with diagnostic of ALS against mycoplasmas have been not detected. In this study, we used LAMPs extracted from M. fermentans PG18. IgM antibodies against LAMPs of these strains were detected in 6/13 (46\%) patients and in 13/42 (31\%) healthy individuals, while IgG antibodies were detected in 4/13 (31\%) patients and in 3/42 (7\%) healthy individuals. We cannot rule out the possibility that ALS patients have higher levels of antibodies to LAMPs than healthy controls, because it was not possible to get a second blood sample from patients. Antibodies against LAMPs of mycoplasmas have been detected in patients with RA and SLE, although antibodies against LAMPs are serological markers of exposure to mycoplasmas, it is important to be cautious with these results, because there is cross-reactivity to self-antigens due to mycoplasma molecular mimicry of self-molecules [17]. Therefore, studies about the participation of LAMPs of mycoplasmas in human diseases are necessary.

Cytadherence is the initial step in the virulence process of pathogenic mycoplasmas. Other biological activities such as generation of hydrogen peroxide and superoxide radicals, competition for and depletion of nutrients or biosynthetic precursors, existence of capsule-like material and electron-dense surface layers or structures, high-frequency phase and antigenic variation, secretion or introduction of mycoplasmal enzymes into the host cell milieu and intracellular residence could be involved in pathogenesis [18]. The mechanisms involved in damage of motor neurons, glial cell and astrocytes are a large number of methylation changes in patients' genes proved to be involved in $\mathrm{Ca}^{++}$dynamics, autotoxicity, oxidative stress, neurotrophic factors receptors, ubiquitin protein, xenobiotic detoxification and DNA repair [19]. The contribution of this study was to show the presence of viable mycoplasmas in the bloodstream of patients with sporadic ALS and the presence of antibodies IgM and IgG against LAMPs of $M$. fermentans, because some biological activities produced by mycoplasmas could be involved in damage to motor neurons, glial cells and astrocytes in patients infected with these microorganisms.

\section{Conclusion}

Epidemiological studies of amyotrophic lateral sclerosis are complicated due to variability of signs and symptoms and low incidence, so it is difficult to include a high number of patients. Mycoplasmas are infectious agents involved in several diseases including neurological diseases (rate 50\% - 80\%) [14] [15]. Our results are similar to those reported in the literature regarding the implication of mycoplasmas in ALS, but in this study we also reported the presence of antibodies against LAMPs of mycoplasmas which may be involved in damage of the host cell. 


\section{Acknowledgements}

This study was supported by Vicerrectoria de Investigación y Estudios de Posgrado. BUAP.

\section{References}

[1] Hardiman, O., van den Berg, H.L. and Kiernan, C.M. (2011) Clinical Diagnosis and Management of Amyotrophic Lateral Sclerosis. Nature Reviews Neurology, 7, 639-649. http://dx.doi.org/10.1038/nrneurol.2011.153

[2] Miller, R.G., Gelinas, D. and O’Connor, P. (2005) Amyotrophic Lateral Sclerosis. American Academy of Neurology, New York.

[3] Brooks, B.R., Miller, R.G., Swash, M. and Munsat, T.L. (2000) El Escorial Revisited: Revised Criteria for the Diagnosis of Amyotrophic Lateral Sclerosis. Amyotrophic Lateral Sclerosis and Other Motor Neuron Disorders, 1, $293-299$. http://dx.doi.org/10.1080/146608200300079536

[4] Kiernan, C.M., Vucic, S., Cheah, C.B., Turner, R.M., Eisen, A., Hardiman, O., Burrell, R.J. and Zoing, C.M. (2011) Amyotrophic Lateral Sclerosis. Lancet, 377, 942-955. http://dx.doi.org/10.1016/S0140-6736(10)61156-7

[5] Pasinelli, P. and Brown, H.R. (2006) Molecular Biology of Amyotrophic Lateral Sclerosis: Insights from Genetics. Nature Reviews Neuroscience, 7, 710-723. http://dx.doi.org/10.1038/nrn1971

[6] Cassell, G.H. and Cole, B.C. (1981) Mycoplasmas as Agents of Human Diseases. The New England Journal of Medicine, 304, 80-89. http://dx.doi.org/10.1056/NEJM198101083040204

[7] Nicolson, L.G. (2007) Systemic Intracellular Bacterial Infection (Mycoplasma, Chlamydia, Borrelia Species) in Neurodegenerative (MS, ALS) and Behavioural Disorders (ADS). I Infectious Diseases Newsletter, 1-9.

[8] Nicolson, L.G. (2008) Chronic Bacterial and Viral Infections in Neurodegenerative and Neurobehavioral Diseases. LabMedicine, 39, 291-299.

[9] Starakis, I., Panos, G., Koutras, A. and Mazokopakis, E.E. (2011) Pathogens and Chronic or Long-Term Neurologic Disorders. Cardiovascular \& Haematological Disorders-Drug Targets, 11, 40-52. http://dx.doi.org/10.2174/187152911795945123

[10] Sidhu, K.M., Rashidbaigi, A., Testa, D. and Liao, M.J. (1995) Competitor Internal Standards for Quantitative Detection of Mycoplasmal DNA. FEMS Microbiology Letters, 128, 207-212. http://dx.doi.org/10.1111/j.1574-6968.1995.tb07524.x

[11] Wang, R.Y., Hu, W.S., Dawson, M.S., Shinh, J.W. and Lo, S.C. (1992) Selective Detection of Mycoplasma fermentans by Polymerase Chain Reaction and by Using a Nucleotide Sequence within the Insertion Sequence-Like Element. Journal of Clinical Microbiology, 30, 245-248.

[12] Bernet, C., Garret, M., De Barbeyrac, B., Bebera, C. and Bonnet, J. (1989) Detection of Mycoplasma pneumoniae by Using the Polymerase Chain Reaction. Journal of Clinical Microbiology, 27, 2492-2496.

[13] Baseman, B.J. and Tully, G.J. (1997) Mycoplasmas: Sophisticated, Re-Emerging, and Burdened by Their Notoriety. Emerging Infectious Diseases, 3, 21-32.

[14] Flores, L.J., Ordoñez, G. and Pineda, B. (2004) Determinación de infecciones sistémicas por Mycoplasma en pacientes con esclerosis lateral amiotrófica clínicamente definida. Archivos de Neurociencias, 9, 195-201.

[15] Nicolson, G.L., Nasralla, M., Haier, J. and Pomfret, J. (2002) High Frequency of Systemic Mycoplasmal Infections in Gulf War Veterans and Civilians with Amyotrophic Lateral Sclerosis (ALS). Journal of Clinical Neuroscience, 9, 525529. http://dx.doi.org/10.1054/jocn.2001.1075

[16] Chambaud, I., Wróblewski, H. and Blanchard, A. (1999) Interaction between Mycoplasma Lipoprotein and the Host Immune System. Trends in Microbiology, 7, 493-499. http://dx.doi.org/10.1016/S0966-842X(99)01641-8

[17] Browning, G.F., Marenda, M.S., Noormohammadi, A.H. and Markham, P.F. (2011) The Central Role of Lipoproteins in the Pathogenesis of Mycoplasmoses. Veterinary Microbiology, 153, 44-50. http://dx.doi.org/10.1016/j.vetmic.2011.05.031

[18] Balish, M.R. and Krause, D.C. (2002) Cythaderence and the Cytoskeleton. In: Razin, S. and Herrmann, R., Eds., Molecular Biology and Pathogenecity of Mycoplasmas, Kluwer Academic Plenum Publisher, New York, 491-518.

[19] Mcgeer, P.L. and Mcgeer, E.G. (2002) Inflammatory Processes in Amyotrophic Lateral Sclerosis. Muscle \& Nerve, 26, 459-470. http://dx.doi.org/10.1002/mus.10191 
Scientific Research Publishing (SCIRP) is one of the largest Open Access journal publishers. It is currently publishing more than 200 open access, online, peer-reviewed journals covering a wide range of academic disciplines. SCIRP serves the worldwide academic communities and contributes to the progress and application of science with its publication.

Other selected journals from SCIRP are listed as below. Submit your manuscript to us via either submit@scirp.org or Online Submission Portal.
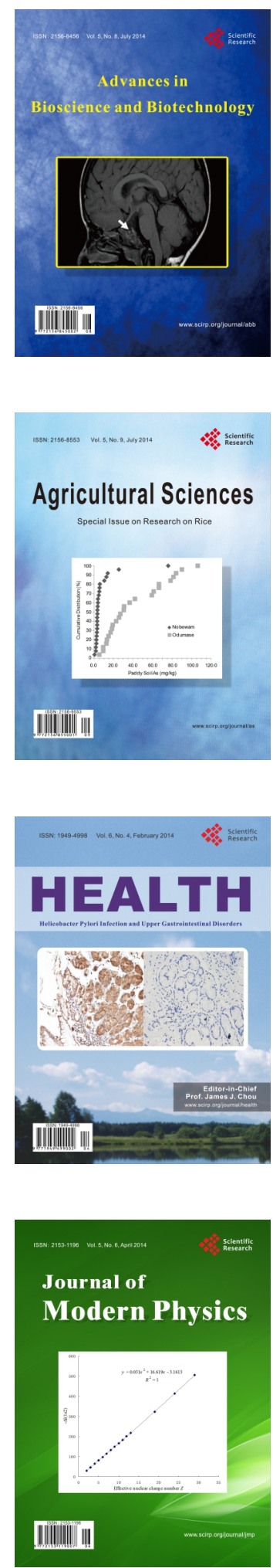
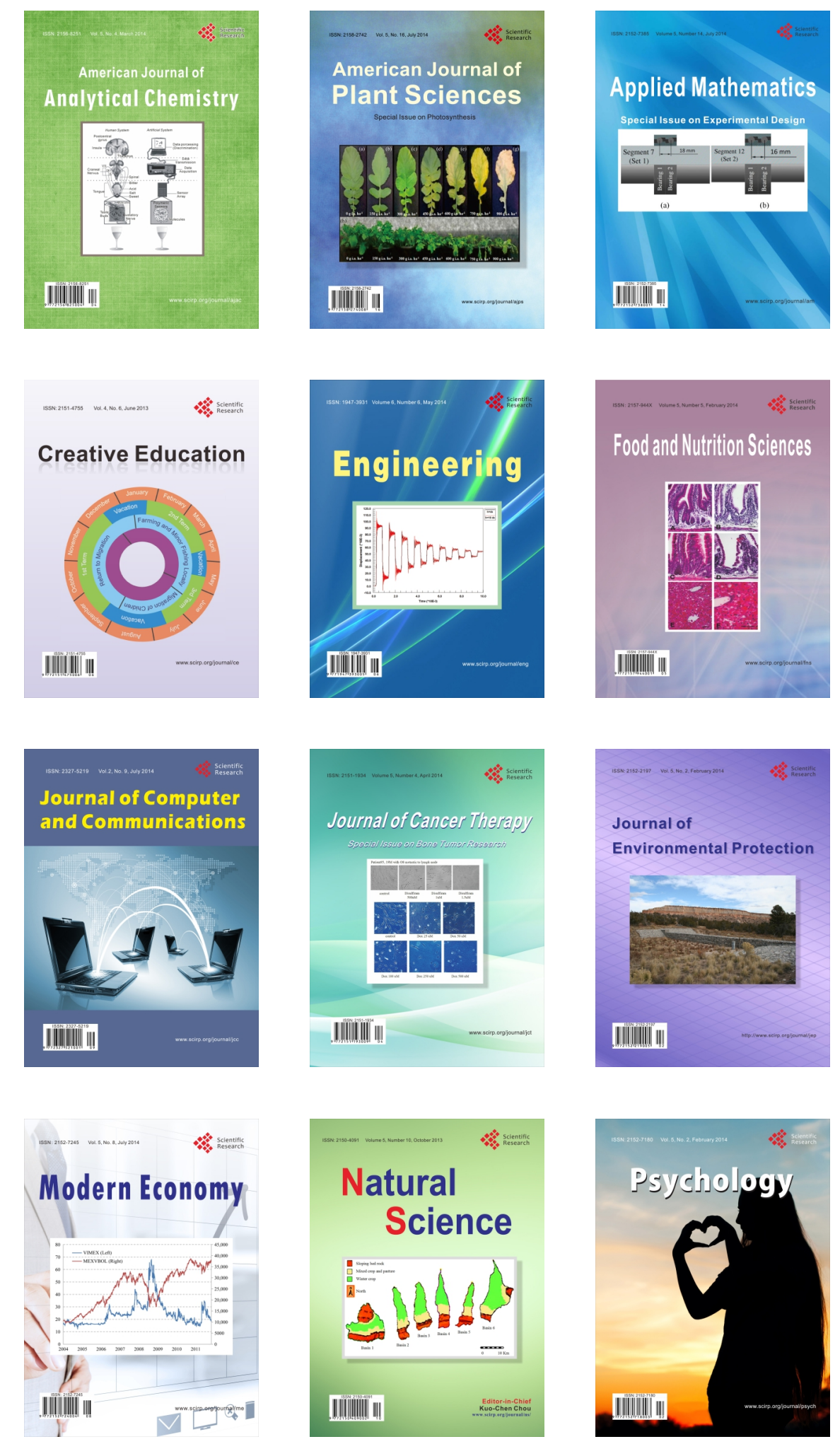